\title{
Advanced Case of Invasive Basal Cell Carcinoma with Extensive Ocular Myiasis
}

\author{
Sudhir M Naik, A Nanjundappa, Rajshekar Halkud, Sumit Gupta
}

\section{ABSTRACT}

Background: Ocular myiasis or ophthalmomyiasis means the infestation of the eye on a background of foul smelling skin infection or advanced case of skin cancers. Older people, immunocompromised patients with orbital carcinomas, diabetics and patients on immunosuppressive therapy, poor environmental sanitation and personal hygiene are prone for this infestation.

Case report: A 72-year-old female reported to us with extensive myiasis of the right eye. Lesion of $4 \times 4 \mathrm{~cm}$ at the medial canthus and the right maxillary region with the right nasal dorsum was infested with maggots. All the larvae were removed with forceps and the wound debrided.

Intervention: The larvae were present for a week and on healing the wound was evaluated with computed tomographic (CT) scan paranasal sinuses with axial and coronal section. As no bony erosion and intracranial extension was noted hence considering the age and diabetic status surgery was not contemplated and the lesion was irradiated.

Conclusion: Ocular myiasis is a rare disease, accompanied by marked inflammatory reactions and secondary bacterial infections with massive destruction and life-threatening consequences, such as intracranial invasion. Prompt management with debridement and radical antibacterial therapy is essential.

Keywords: Ocular myiasis, Basal cell carcinoma, Debridement, Intracranial invasion, Radiotherapy.

How to cite this article: Naik SM, Nanjundappa A, Halkud R, Gupta S. Advanced Case of Invasive Basal Cell Carcinoma with Extensive Ocular Myiasis. Int J Head and Neck Surg 2013;4(1):36-40.

\section{Source of support: Nil}

\section{Conflict of interest: None}

\section{INTRODUCTION}

Myiasis is the invasion of living animal tissue by fly larvae (maggots) and the term was coined by Hope. ${ }^{1,2}$ Ocular myiasis or ophthalmomyiasis means the infestation of the eye by these larvae., ${ }^{3,4}$ Ocular myiasis in humans was first reported by Keyt in 1900 while in India by Elliot in $1910 .^{5}$ The infestation in India is usually by larvae of the sheep nose botfly, Oestrus ovis. ${ }^{2}$ The adult flies give birth to live young (larvae) which are capable of parasitizing hosts immediately. ${ }^{4}$

The larvae can survive in the lacrimal secretion, erode the conjunctiva and destroy the cornea causing orbital damage with permanent blindness. ${ }^{4}$ Older people, immunocompromised patients with orbital carcinomas, diabetics, and patients on immunosuppressive therapy, poor environmental sanitation and personal hygiene and handling the infested cattle or the fly itself all are responsible factors. ${ }^{6}$ The larvae start eating the tissue beneath the skin and grow into large maggots. ${ }^{4}$ The invasive parasitic larvae almost invariably cause massive destruction of orbital tissue, or the involved skin accompanied by marked inflammatory reactions and secondary bacterial infections. ${ }^{3}$

We report a case of external orbital myiasis with infraorbital invasive basal cell carcinoma (BCC) with extensive myiasis managed with exenteration and debridement. After healing the lesion was irradiated with external beam radiotherapy.

\section{CASE REPORT}

A 72-year-old female reported to us with extensive myiasis of the right eye. After examining the eye extensive myiasis were seen in the right eye and in the lesion of $4 \times 4 \mathrm{~cm}$ at the medial canthus and the right maxillary region below the eyelid. The right sided nasal dorsum was destroyed with the soft triangle remaining intact on the right. The foul smelling crust was removed and a small guaze piece soaked in turpentine was kept on the lesion. The maggots started coming out of the lesion. All the maggots coming out were removed using a Blakesley's nasal forceps and 100 to 150 were harvested by this method. Later pockets in and around the lateral maxillary skin, nasal dorsum and cavity, medial canthal region, upper eyelid along the conjunctival region, frontal sinus region were blindly explored and removed. The patient was admitted and was put on broad spectrum antibiotics with her blood profile was investigated and contrast enhanced computed tomographic (CT) scan of paranasal sinus showed no bony erosion seen with no intracranial spread seen. A large irregular ulcerated solid mass in the infraorbital region was seen. Mass had a heterogeneous and patchy content. All the sinuses were normal and brain parenchyma was within normal limits.

The patient had a history of invasive ulceroproliferative lesion on the right infraorbital area for which she was applied a rural medicine. Later the wound was neglected and reported to us with maggots in the right eye and nasal dorsum. Daily maggots removal was done and the wound cleaned and the maggots were cleared. The maggots were 
removed for 3 alternate days and later no more maggots were seen later (Figs 1 to 3 ). The wound healed after 10 days of continuous dressing. The clinical examination showed no light perception in her right eye; the eyelid was thickened and there was a necrotic, loose tissue seen. The cornea was opaque and the fundus could not be examined.

Visual acuity in the patient's left eye was 6/24 and intraocular pressure was normal. A mature cataract was seen in the left eye. The ocular bulbus, retrobulbar space, extraocular muscles and optic nerve were normal in the left eye and no intracranial invasion was found by CT scan (Figs 4 and 5). Histopathology of the lesion was confirmed as BCC and the patient was followed up for metastasis. The larvae were identified to be Oestrus ovis dipterous fly larvae. Locoregional examination revealed no nodes and metastasis. Rest of the blood parameters were within normal limits. The patient was an uncontrolled diabetic and was now controlled with human insulin. Due to the poor performance status, diabetic status, old age, and extensive disease surgery and reconstruction was not contemplated and the lesion was irradiated with low dose radiation.

\section{DISCUSSION}

Myiasis can be asymptomatic in some cases while in some cases may lead to mild-to-severe disturbances and even prove fatal. ${ }^{7}$ Flies are small-winged arthropods of the class Insecta which lay eggs leading to larval tissue invasion causing myiasis, also act as biologic or mechanical vectors of protozoal, viral, bacterial or helminthic diseases. ${ }^{1}$

In flies of Oestridae family, the complete life cycle takes place in cattle, and infestation frequently occurs in cattle when a fly transfers eggs to wounds or broken skin of human beings. ${ }^{7}$ The larvae hatch in a week and are of 5 to $20 \mathrm{~mm}$ in length, $3 \mathrm{~mm}$ in diameter and tunnel into the host tissues by destroying them. ${ }^{7}$ Ocular myiasis in humans are commonly caused by $H$. bovis, infestation is rare because humans are accidental hosts, while the flies commonly affects primarily wounds of the skin. Infections with purulent secretions and blood and body secretions are the most common factors that attract flies. ${ }^{7}$

Ophthalmomyiasis is called external when it is limited to the superficial periocular tissues and includes palpebral and conjunctival myiasis without conjunctival and scleral penetration. ${ }^{3}$ It is called internal or orbital myiasis when it penetrate the conjunctiva and sclera and migrate into the subretinal space which is rare in type. ${ }^{1}$ The incidence of ophthalmomyiasis is less than $5 \%$ of human myiasis and orbital myiasis is the least common form of ophthalmomyiasis. ${ }^{1}$ Most of the patients with ophthalmomyiasis are elderly demented patients who cannot take
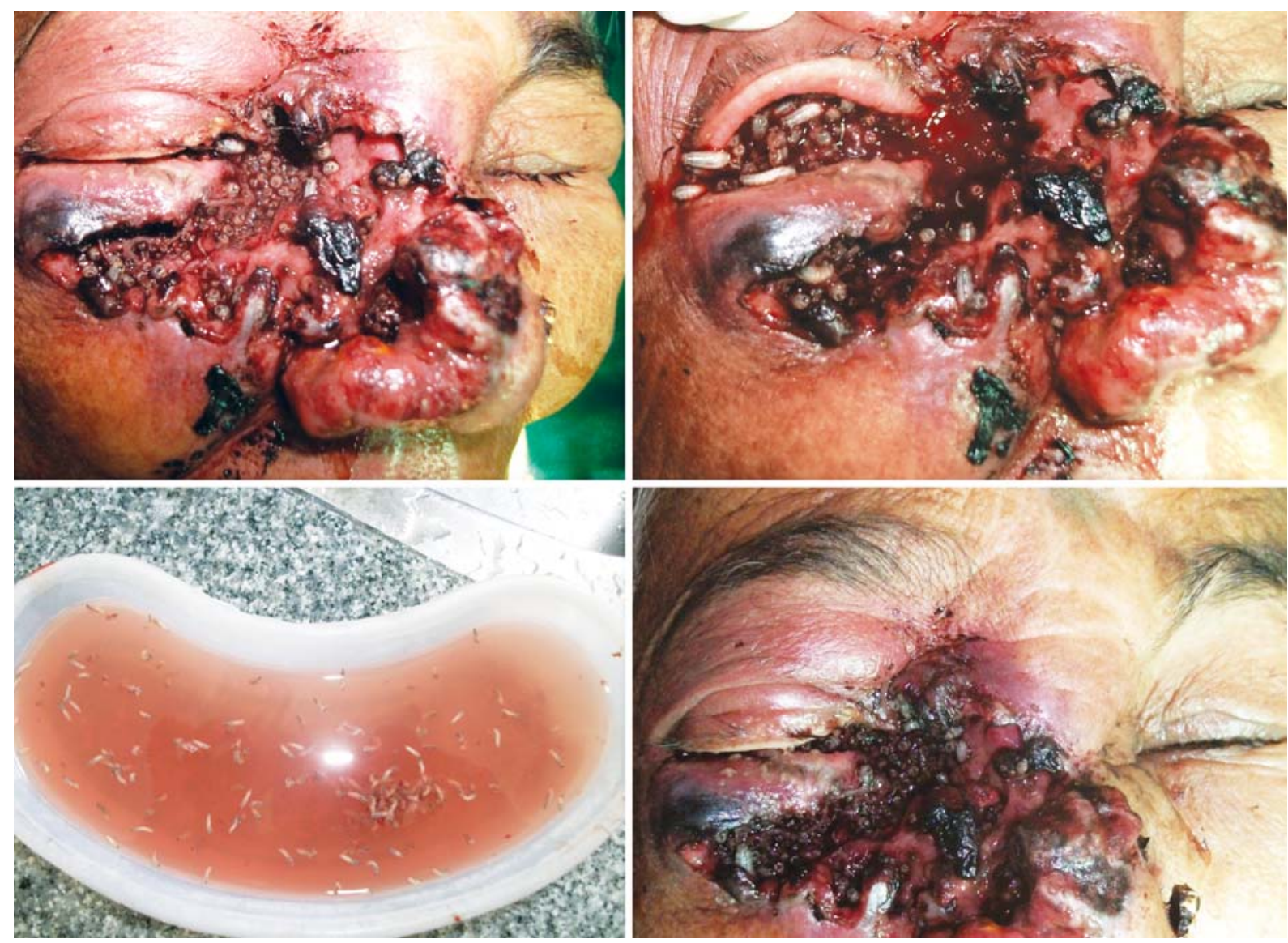

Fig. 1: Maggots seen on the first day and the huge larval harvest 

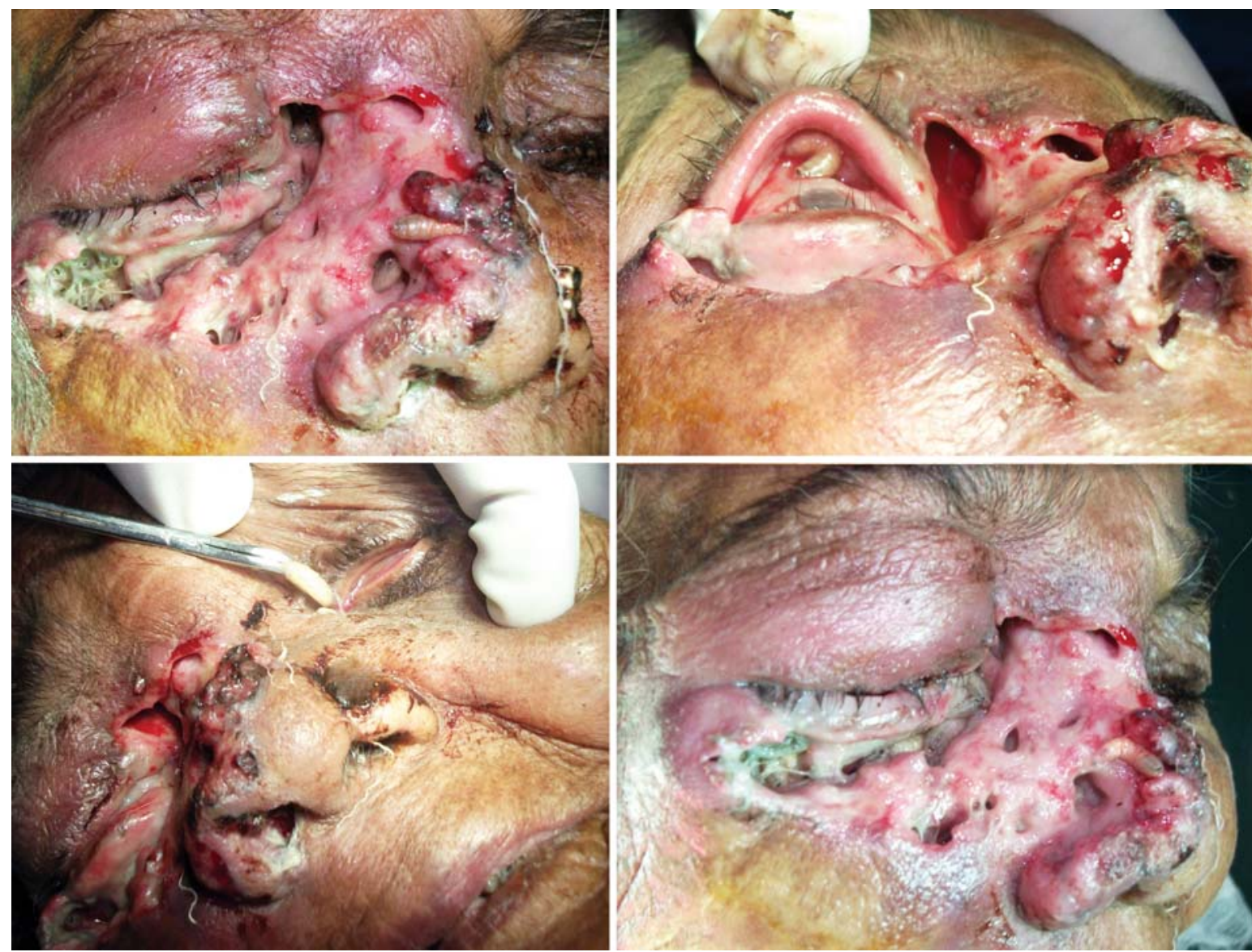

Fig. 2: Reduced maggots number on day 3, with the open pockets seen in the other eye also
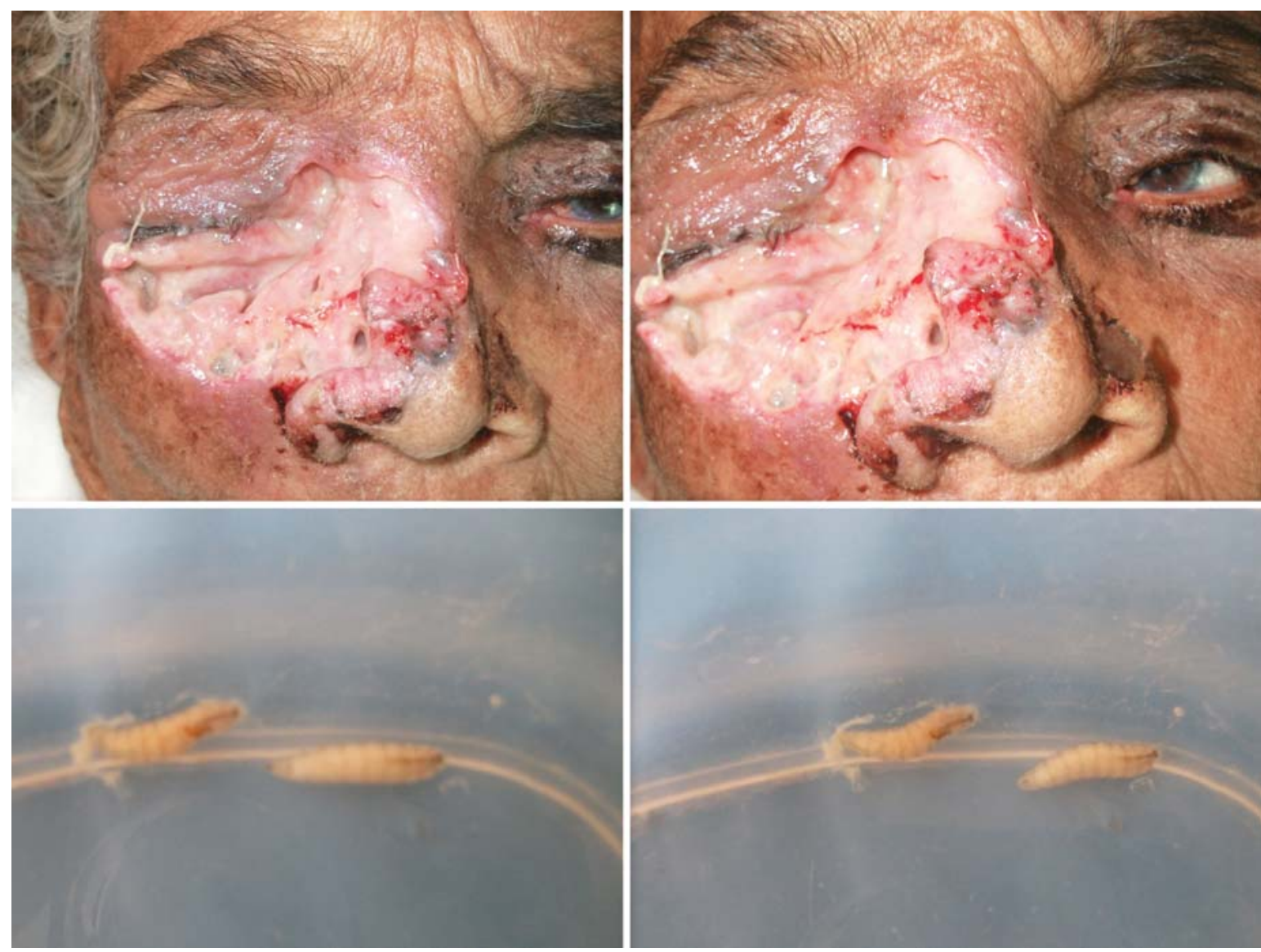

Fig. 3: Only two larvae seen on day 5 with slough of the wound 

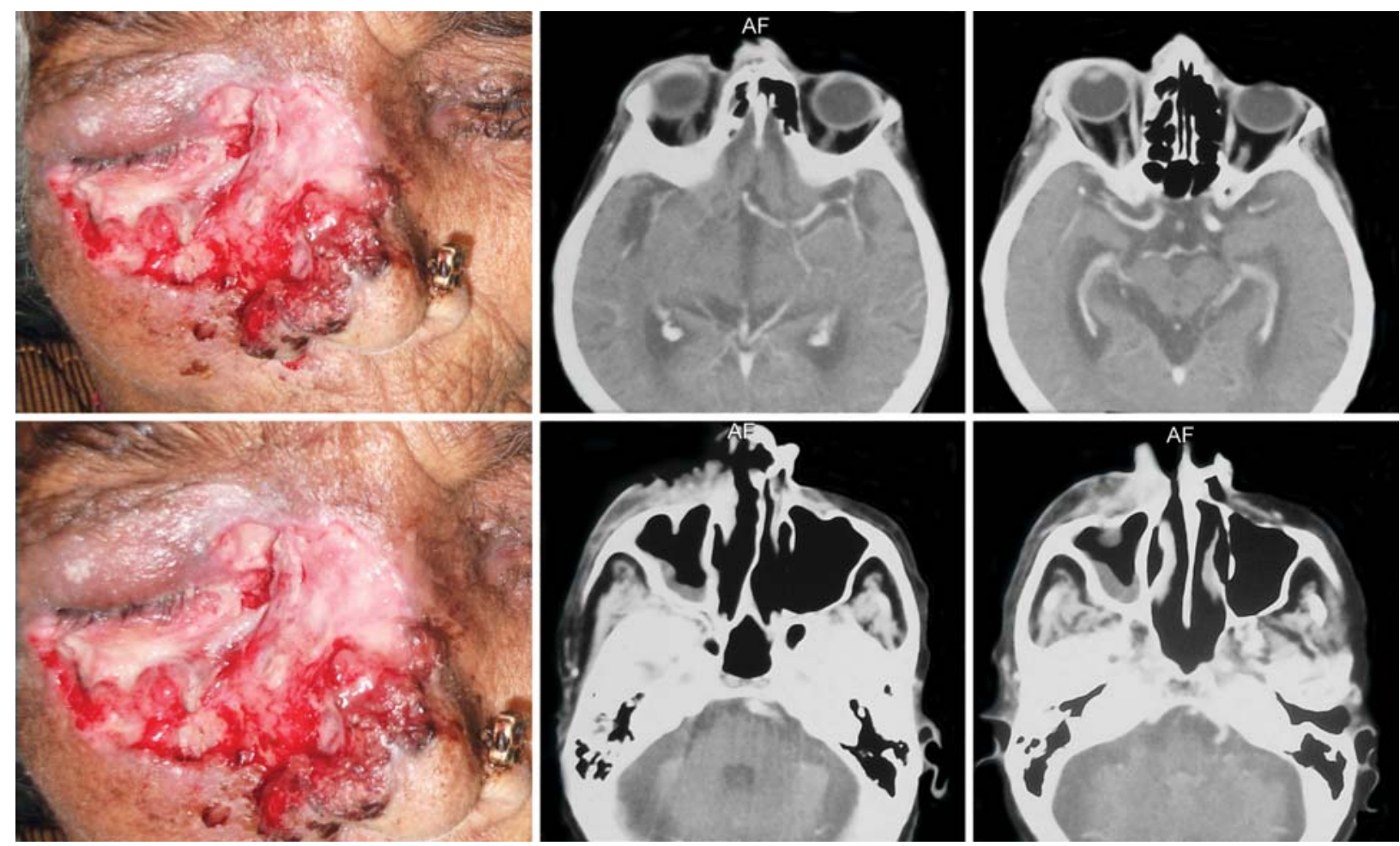

Fig. 4: Healing wound on day 7 with axial CT images showing no bony erosion

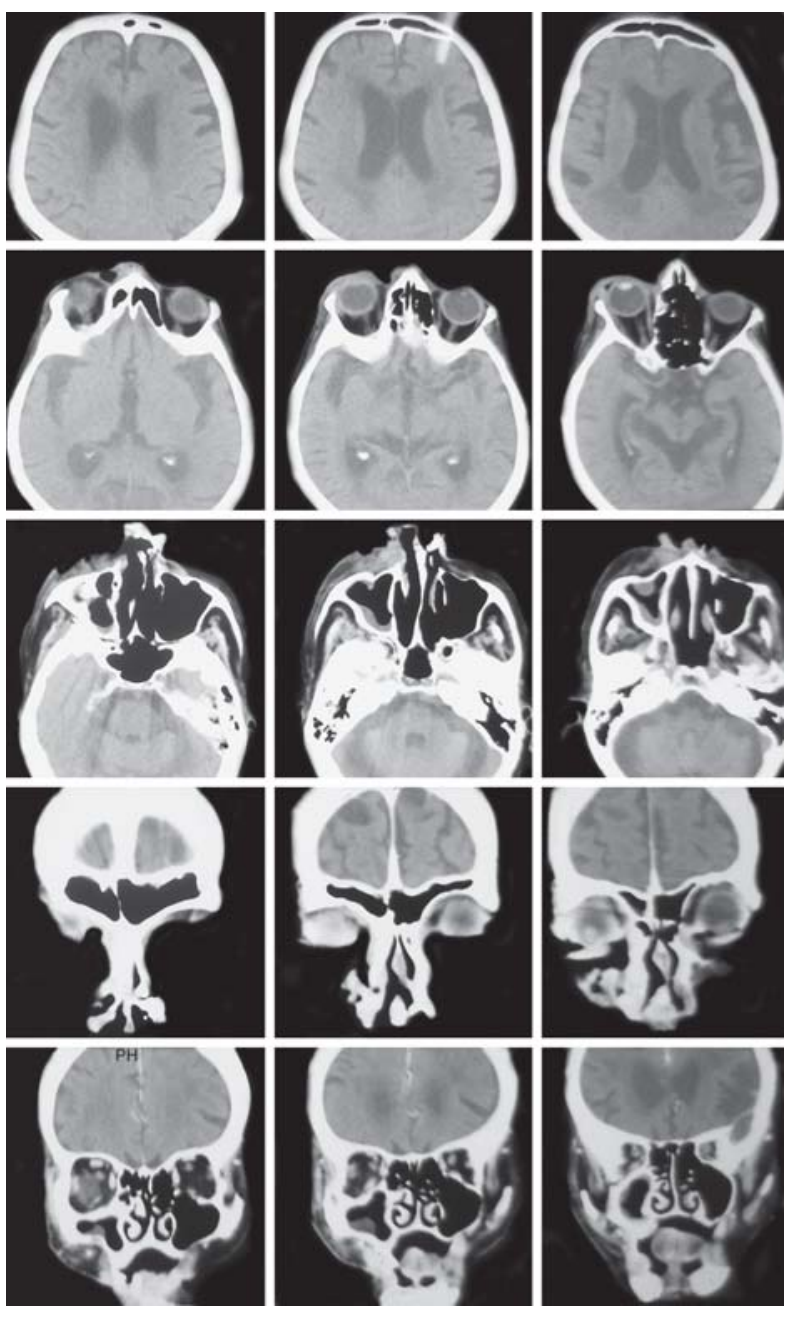

Fig. 5: CT scan axial and coronal images showing no intracranial and no sinus wall erosion care of themselves, low socioeconomic status and poor hygiene, farmers, laborers or beggars, pre-existing ocular diseases leading onto infestation. ${ }^{1}$ While the incidence in pediatric age group is rare infestation is possible over gonococcal conjunctivitis whereas in adults its predisposed by preoperated ulcerated and sloughed skin and soft tissue.?

Baliga et al reported orbital myiasis on infected ulcerated tissue of BCC. ${ }^{2}$ Bosniak et al, Agarwall et al reported orbital myiasis in cases with BCC in a lower eyelid. ${ }^{8,9}$ Ocular myiasis can be treated by removing all invading organisms, proper care of wounds and controlling the almost inevitable secondary bacterial infections. ${ }^{3}$ Various chemicals recommended to narcotize or kill larvae, such as naphtha, ether, chloroform, cocaine and turpentine which should be used sparingly in ocular lesions., ${ }^{8,9}$

BCC is a slow-growing, locally invasive malignant epidermal skin tumor which infiltrates tissues in a threedimensional contiguous fashion through the irregular growth of subclinical finger-like outgrowths. ${ }^{10-12}$

Seen commonly in older patients, especially in the head and neck areas eyelid and nose where exposure of ultraviolet radiation is frequent and intense. ${ }^{13}$ Its a slow growing, nonaggressive tumor, while WHO describes it as 'a locally invasive, slowly spreading tumor which rarely metastasize, arising in the epidermis or hair follicles and in which, in particular, the peripheral cells usually simulate the basal cells of the epidermis' ${ }^{14}$ Most of the morbidity is related to 
local tissue invasion and destruction, particularly on the head and neck as the metastasis is very rare. ${ }^{15}$ Seven variants are reported with the nodular, cystic, ulcerated (rodent ulcer), superficial, morphoeic (sclerosing), keratotic and pigmented ones. $^{16}$

Treatment of choice is usually surgery while cryotherapy, radiotherapy, curettage and electrodessication treatment are also reported. ${ }^{17}$ Also reported as treatment modalities are topical 5-fluorouracil (5-FU) ointment, laser treatment and systemic chemotherapy. ${ }^{18}$ Histological identification of the subtypes and exact configuration of the anatomic location that can increase the risk of spread and defining the limitations of available treatment modalities are necessary before venturing out for definite treatment. ${ }^{19}$ Usually local flaps are sufficient to reconstruct the surgical defects after clearing the tumor margins. ${ }^{19}$

We preferred radiotherapy as the lady was old and diabetic with extensive periorbital invasion. As the maggots infestation was very intense with the larvae coming out from the other eye and possibility for intracranial invasion due to proximity of skull base the invasive margins were felt deep. Even as the orbital apex was not involved on CT scan, breach of the skull base was not rued out. As the orbital infiltration not seen, orbital exenteration was not done.

\section{CONCLUSION}

Ocular myiasis is a rare disease, accompanied by marked inflammatory reactions and secondary bacterial infections with massive destruction and life-threatening consequences, such as intracranial invasion. Prompt management with debridement and radical antibacterial therapy is essential while definitive treatment for the underlying skin pathology is mandatory.

\section{REFERENCES}

1. Kersten RC, Shoukrey NM, Tabbara KF. Orbital myiasis. Ophthalmology 1986;93(9):1228-32.

2. Baliga MJ, Davis P, Rai P, Rajasekhar V. Orbital myiasis: A case report. Int J Oral Maxillofac Surg 2001;30:83-84.

3. Caca I, Unlu K, Cakmak SS, Bilek K, Sakalar YB, Unlu G. Orbital myiasis: Case report. Jpn J Ophthalmol 2003;47:412-14.

4. Raina UK, Gupta M, Kumar V, Ghosh B, Sood R, Bodh SA. Orbital myiasis in a case of invasive basal cell carcinoma. Oman J Ophthalmol 2009;2(1):41-42.

5. Sivaramasubramanyam P, Sadanand AV. Opthalmomyiasis. Br J Ophthalmol 1968;52:52-65.
6. Sachdev MS, Harsh Kumar, Jain AK, Arora R, Dada VK. Destructive ocular myiasis in a non-compromised host. Indian J Ophthalmol 1990;38:184-86.

7. Cordero-Moreno R. Etiologic factors in tropical eye diseases. Am J Ophthalmol 1973;75:349-64.

8. Bosniak SL, Schiller JD. Ophthalmomyiasis in an eyelid reconstruction. Am J Ophthalmol 1990;109:101-02.

9. Agarwall DC, Singh B. Orbital myiasis - a case report. Indian J Ophthalmol 1990;38(4):187-88.

10. Albright SD. Treatment of skin cancer using multiple modalities. J Am Acad Dermatol 1982;7(2):143-71.

11. Breuninger H, Dietz K. Prediction of subclinical tumor infiltration in basal cell carcinoma. J Dermatol Surg Oncol 1991; 17:574-78

12. Lo JS, Snow SN, Reizner GT, et al. Metastatic basal cell carcinoma report of twelve cases with a review of the literature. J Am Acad Dermatol 1991;24:715-19.

13. Jacobs GH, Rippey JJ, Altini M. Prediction of aggressive behavior in basal cell carcinoma. Cancer 1982;49(3):533-37.

14. Lalloo MT, Sood S. Head and neck basal cell carcinoma: treatment using a $2 \mathrm{~mm}$ clinical excision margin. Clin Otolaryngol Allied Sci 2000;25(5)370-73.

15. Gilbody JS, Aitken J, Green A. What causes basal cell carcinoma to be the commonest cancer? Aust J Public Health 1994;18: 218-21.

16. Telfer NR, Colver GB, Bowers PW. Guidelines for the management of basal cell carcinoma. Br J Dermatol 1999;141: 415-23.

17. Tifikciôglu YO, Karaaslan O, Aksoy HM, Aksoy B, Kocer U. Basal cell carcinoma in Turkey. J Dermatol 2006;33(2):91-95.

18. Levine $\mathrm{H}$. Cutaneous carcinoma of the head and neck: Management of massive and previously uncontrolled lesions. Laryngoscope 1983;93(1):87-105.

19. Nakayama M, Tabuchi K, Nakamura Y, Hara A. Basal cell carcinoma of the head and neck. J Skin Cancer 2011;P7.

\section{ABOUT THE AUTHORS}

\section{Sudhir M Naik (Corresponding Author)}

Fellow, Department of Head and Neck Oncosurgery, Kidwai Institute of Oncology, Bengaluru, Karnataka, India, e-mail: sud223@gmail.com

\section{A Nanjundappa}

Professor, Department of Head and Neck Oncosurgery, Kidwai Institute of Oncology, Bengaluru, Karnataka, India

\section{Rajshekar Halkud}

Associate Professor, Department of Head and Neck Oncosurgery Kidwai Institute of Oncology, Bengaluru, Karnataka, India

\section{Sumit Gupta}

Fellow, Department of Head and Neck Oncosurgery, Kidwai Institute of Oncology, Bengaluru, Karnataka, India 